\title{
Growth and Productivity of Wheat under Tillage Systems and Residue Loads in Tarai Region of Uttarakhand, India
}

\author{
Sirazuddin $^{1 *}$, V. Pratap. Singh ${ }^{1}$, Subhash Chandra ${ }^{1}$, S.P. Singh ${ }^{1}$, S.K. Guru ${ }^{2}$, \\ Navneet Pareek ${ }^{3}$, Arya Kumar Sarvadamana ${ }^{1}$ and Arunima Paliwal ${ }^{4}$ \\ ${ }^{1}$ Department of Agronomy, G.B.P.U.A\& T, Pantnagar, India \\ ${ }^{2}$ Department of Plant Physiology, G.B.P.U.A\& T, Pantnagar, India \\ ${ }^{3}$ Department of Soil Science, G.B.P.U.A\& T, Pantnagar, India \\ ${ }^{4}$ Department of Agronomy, V.C.S. G. Uttarakhand University of Horticulture \& Forestry, \\ Ranichauri, India \\ *Corresponding author
}

\section{A B S T R A C T}

\begin{tabular}{|l|}
\hline Ke y w o r d s \\
Emergence, Rice \\
residue load, \\
Tillage, Wheat, \\
Zero tillage, Yield \\
\hline Article Info \\
\hline $\begin{array}{l}\text { Accepted: } \\
\text { 04 July 2019 } \\
\text { Available Online: } \\
\text { 10 August } 2019\end{array}$ \\
\hline
\end{tabular}

\section{Introduction}

Rice-wheat cropping system (RWCS) is of immense importance for ensuring food security in India. The highly mechanized, yield in both the years.
Field experiments were conducted in D-2 block of Norman E. Borlaug Crop Research Centre of G.B. Pant University of Agriculture and Technology, Pantnagar, Distt. Udham Singh Nagar (Uttarakhand) during 2017-18 and 2018-19. The objectives of the investigation were to study effect of tillage systems and residue loads on the initial establishment, growth attributes and productivity of wheat. The soil of the experimental plot was clay loam high in organic carbon $(0.80 \%)$, medium in available nitrogen (246.3 $\mathrm{kg} / \mathrm{ha})$, high in available phosphorus $(22.7 \mathrm{~kg} / \mathrm{ha})$ and medium in available potassium $(180.3 \mathrm{~kg} / \mathrm{ha})$ with neutral $\mathrm{pH}$ (6.8). Field experiments were laid in strip plot design with three tillage systems viz. conventional tillage (CTW), reduced tillage (RTW) and zero tillage (ZTW) systems in vertical strip and three residue loads viz. no residue, 3 and 5 t/ha in horizontal strips and replicated thrice. Tillage systems and residue loads did not influence emergence count and plant height significantly during both the years. Tillage systems did not affect number of shoots $/ \mathrm{m}^{2}$ significantly at 50 and 90 DAS during both the years of experimentation. Residue load of 3 t/ha was at par with no residue produced significantly higher number of shoots $/ \mathrm{m}^{2}$ than $5 \mathrm{t} / \mathrm{ha}$ at 50 and 90 DAS during both the years. The magnitude of increase in grain yield of wheat by RTW over ZTW and CTW was 3.39 and $5.63 \%$, respectively in the first year. In the second year, ZTW produced comparable grain yield with CTW and RTW. Residue load did not influence the grain 
threatened by degrading soils, declining water availability and environmental pollution as a result of high cropping intensity, imbalanced nutrition along with high input use in intensive system tillage. In spite of all these limitations, improvement in productivity of RWCS is a major concern to keep up food supply pace with population growth in India. Among numerous limitations of RWCS, the burning of crop residue is the major one. In India, the total amount of crop residue generated is estimated to be $350 \times 10^{6} \mathrm{~kg} /$ year out of which, wheat residue constitutes about $27 \%$ and rice residue about $51 \%$ (Mandal et al., 2004). Almost complete crop residue burning in the field is a common practice particularly in combine harvested fields. With the introduction of combine harvesters, more than $75 \%$ of the rice area is harvested mechanically in north-western parts of the Indo-Gangetic Plains (IGP). Combine harvester leaves behind a swath of loose as well as standing rice residues, which interfere with land preparation and seed drill operations for wheat planting. Management of the rice straw especially the loose straw is a major confront. Thus, farmers usually burn the rice residue onto their fields to get rid of huge amount residue and to ensure timely sowing of wheat crop and save the energy on land preparation.

However, burning of residues is not a healthy practice owing to reasons explained above. Therefore, there is need to manage the rice residue but in a cost effective manner and without putting penalty on wheat productivity. Several approaches or practices are under way to get rid of residue burning. Two approaches i.e. with and without incorporation of residue can be though off in this regard. With the development of novel seeding drills like happy seeder, which cut through crop residue for zero-tillage crop planting can be used. However, when sowing is done in loose straw and standing stubbles, it leaves a thick layer of mulch particularly in the loose straw strips, which interfere with the germination process and does not match with the mind set of clean cultivation of the farmers. Therefore, removal of loose straw is crucial to surmount the cited impediments. Hence, how much residue load is to be retained and what amount of tillage intensity is needed to manage different residue loads are the major questions which need to be addressed at commercial field level. Keeping these issues in mind, the experiments were conducted to study effect of tillage systems and residue loads on the initial establishment, growth attributes and productivity of wheat.

\section{Materials and Methods}

A field experiment was conducted in $D-2$ block of Norman E. Borlaug Crop Research Centre of G.B. Pant University of Agriculture and Technology, Pantnagar, Distt. Udham Singh Nagar (Uttarakhand) during 2017-18 and 2018-19. The soil of the experimental plot was clay loam high in organic carbon $(0.80 \%)$, medium in available nitrogen $(246.3 \mathrm{~kg} / \mathrm{ha})$, high in available phosphorus $(22.7 \mathrm{~kg} / \mathrm{ha})$ and medium in available potassium $(180.3 \mathrm{~kg} / \mathrm{ha})$ with neutral $\mathrm{pH}$ (6.8). Field experiments were laid in strip plot design with three tillage systems viz. conventional tillage (CTW), reduced tillage (RTW) and zero tillage (ZTW) systems in vertical strip and three residue loads viz. no residue, 3 and 5 t/ha in horizontal strips and replicated thrice. During Kharif season, puddle transplanted rice crop was taken in strips as per proposed layout. It was harvested by combine at 30 and $50 \mathrm{~cm}$ height and manually in no residue plots. Loose straw was removed manually simulating as removed by Baler. In conventional and reduced tillage treatments, tractor operated harrow, rotavator and plank were used for land preparation. In all the plots having 30 and $50 \mathrm{~cm}$ stubbles, sowing was done by Happy seeder whereas, in case of no residue, sowing was done by zero till seed drill. To quantify the tonnage of residue, $1 \mathrm{~m}^{2}$ area was clipped from ground 
and oven dry weight was recorded and converted into t/ha. The mean was 3 and $5 \mathrm{t} / \mathrm{ha}$ for 30 and $50 \mathrm{~cm}$ stubble height, respectively. In all the plots, pre-sowing irrigation was given. In zero tilled plots, sowing was done at relatively high moisture content $(15.4 \%)$ while in tilled plots, sowing was done at $13.2 \%$ moisture content.

Sowing of wheat variety, UP 2628 during Rabi 2017-18 and 2018-19 was done by happy seeder at row to row spacing of $20 \mathrm{~cm}$ on Nov. 25, 2017 and Nov. 27, 2018 in case of zero tillage while in conventional and reduced tillage, sowing was done directly by happy seeder on Dec. 1, 2017 and Dec. 2, 2018, respectively. The plots where rice residue was completely removed, sowing was done by conventional zero till-ferti-seed drill in case of all tillage system. After sowing furrows were covered under conventional sown plots. In zero till plots, seed rate was $120 \mathrm{~kg} / \mathrm{ha}$ and 100 $\mathrm{kg} / \mathrm{ha}$ for other tillage systems. A dose of 150 $\mathrm{kg}$ nitrogen, $60 \mathrm{~kg} \mathrm{P}_{2} \mathrm{O}_{5}$ and $40 \mathrm{~kg} \mathrm{~K}_{2} \mathrm{O}$ per hectare was applied through urea (46 per cent $\mathrm{N})$ and NPK mixture (12:32:16 \% of N, P and $\mathrm{K})$. The maximum and minimum temperature at the time of sowing of wheat was 28.7, $11.3^{\circ} \mathrm{C}$ (Figure 1) and $26.5,11.8^{\circ} \mathrm{C}$ (Figure 2) during 2017-18 and 2018-19, respectively

The emergence count was taken by counting number of emerged seedlings from the $1 \mathrm{~m}+$ $1 \mathrm{~m}$ row length. Emergence count was expressed as number of emerged seedlings $/ \mathrm{m}^{2}$. The shoot count was taken by counting number of shoots from the $1 \mathrm{~m}+1 \mathrm{~m}$ row length at 50 and 70 days crop growth stages then was converted to $1 \mathrm{~m}^{2}$ and expressed as number of shoots per $\mathrm{m}^{2}$. The height of wheat plant was measured $(\mathrm{cm})$ with the help of a meter scale from the base of plant to the tip of fully opened leaf till panicle emergence but after panicle emergence, the height was measured from the base of the plant to the tip of the upper most spikelet and expressed as average plant height in $\mathrm{cm}$. Plants falling within the $50 \mathrm{~cm}$ row length from two representative spots from each plot were cut close to the ground surface and dried in a hot air oven maintained at $70 \pm 2{ }^{\circ} \mathrm{C}$ till constant dry weight. Dry matter of plants was recorded and expressed in $\mathrm{g} / \mathrm{m}^{2}$. After leaving 4 rows both side of the plot (North \& South) and 2.5 $\mathrm{m}$ each (East and West) from the bund, net plot area of $5 \mathrm{~m} \times 2 \mathrm{~m}=10 \mathrm{~m}^{2}$ in the centre was harvested for yield. The grains were removed by Pullman thresher and recorded plot wise. The grain yield was expressed at 14 per cent moisture. The final weight was recorded in $\mathrm{kg} / \mathrm{plot}$ and converted into t/ha.

\section{Results and Discussion}

\section{Emergence count $/ \mathrm{m}^{2}$}

Tillage systems and residue loads did not influence emergence count $/ \mathrm{m}^{2}$ significantly (Table 1) during both the years of experimentation. Among tillage systems, zero tillage wheat recorded numerically more emergence count $/ \mathrm{m}^{2}$ over CTW and RTW during both the years. Since in ZTW plots, sowing was done at relatively higher seed rate and moisture content and seeds were not covered. It might have facilitated better emergence of seeds in ZTW conditions. In case of residue management practices, plots having no residue recorded numerically higher emergence count $/ \mathrm{m}^{2}$ over plots having 3 and 5 t/ha residue loads either incorporated or retained on the soil. Presence of residues might have led to relatively poor contact between seed and soil which led to lower emergence count $/ \mathrm{m}^{2}$.

\section{Number of shoots $/ \mathrm{m}^{2}$}

Tillage systems did not affect number of shoots $/ \mathrm{m}^{2}$ significantly at 50 and 90 DAS during both the years of experimentation (Table 2). Numerically higher number of 
shoots $/ \mathrm{m}^{2}$ was recorded in CTW and RTW in the first and second year, respectively. The magnitude of increase between 50 and 90 DAS was $3.15,4.57,3.21$ and $3.33,2.27$, $1.49 \%$ in case of CTW, RTW and ZTW during first and second year, respectively. Residue load significantly influenced the number of shoots $/ \mathrm{m}^{2}$ at 50 and 90 days stage during both the years except at 50 days stage during first year. Residue load of $3 \mathrm{t} / \mathrm{ha}$ was at par with no residue recorded significantly higher number of shoots $/ \mathrm{m}^{2}$ over $5 \mathrm{t} / \mathrm{ha}$ residue load at 50 and 90 days stage during both the years of experimentation. The magnitude of increase in number of shoots $/ \mathrm{m}^{2}$ by $3 \mathrm{t} / \mathrm{ha}$ residue load over no residue and $5 \mathrm{t} / \mathrm{ha}$ residue load was 2.51, 5.48 and 2.00, 4.27 at 90 DAS during first and second year, respectively. The findings revealed the negative impact of higher load of residue on number of shoots $/ \mathrm{m}^{2}$. However, with reduction in residue load to $3 \mathrm{t} / \mathrm{ha}$, tillering was comparable with no residue. The other major contributing factors for higher number of shoots $/ \mathrm{m}^{2}$ under residue load 3 t/ha were better root density and soil moisture availability.

\section{Plant height}

With the advancement of crop age, there was a progressive increase in the plant height and the maximum value reached at maturity. Plant height in general was more in the first year as compared to second year. During both the years, different tillage systems and residue loads did not influence the plant height significantly (Table 3 ) at various crop growth stages (50, 90 and at maturity). However, RTW and ZTW recorded numerically maximum plant height during first and second year, respectively. Residue loads 3 and 5 t/ha recorded more plant height as compared to no residue. Rajkhowa and Borah (2008) also noted the similar findings.

Fig.1 Weekly weather pattern for Rabi season 2017-18

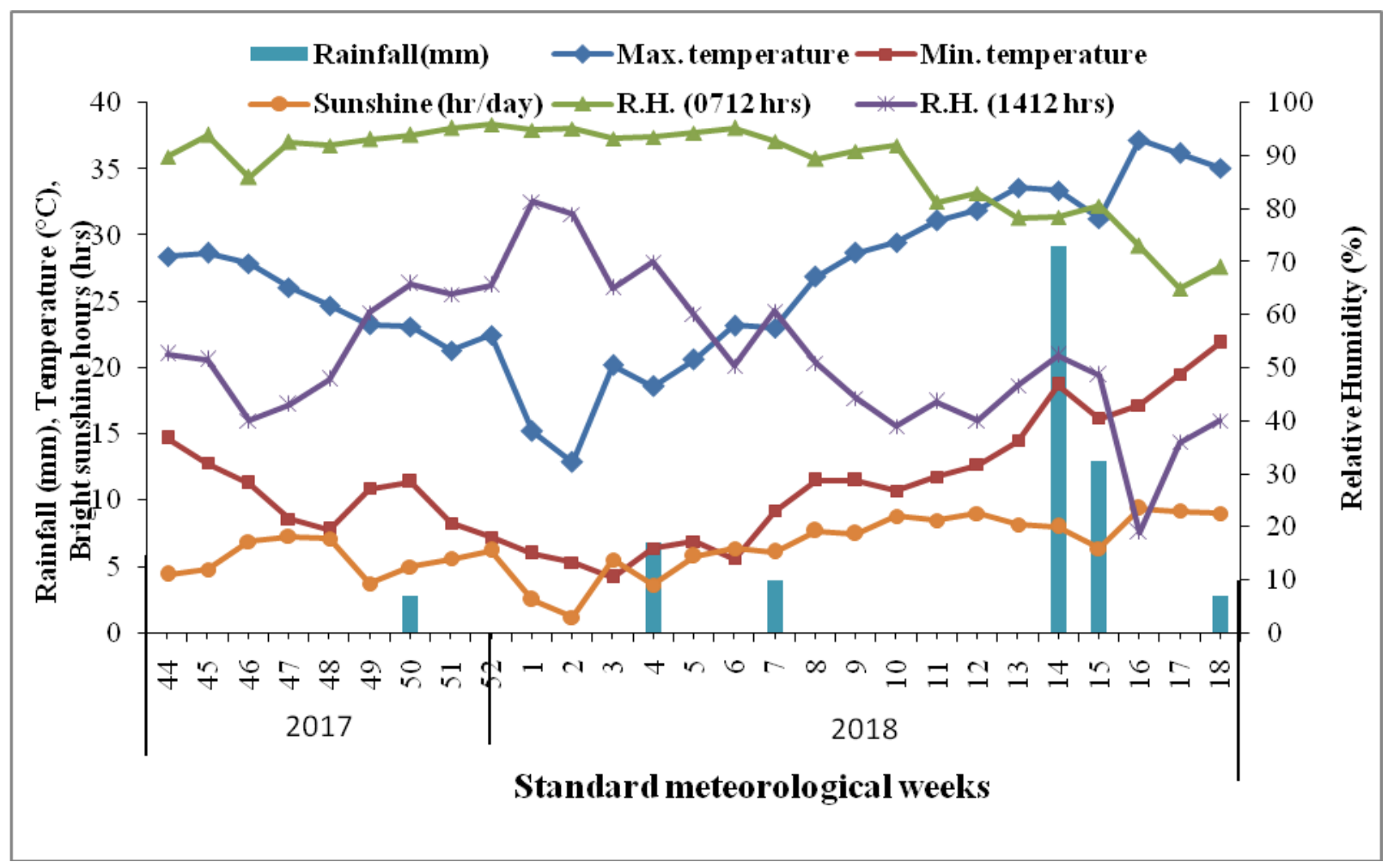


Fig.2 Weekly weather pattern for Rabi season 2018-19

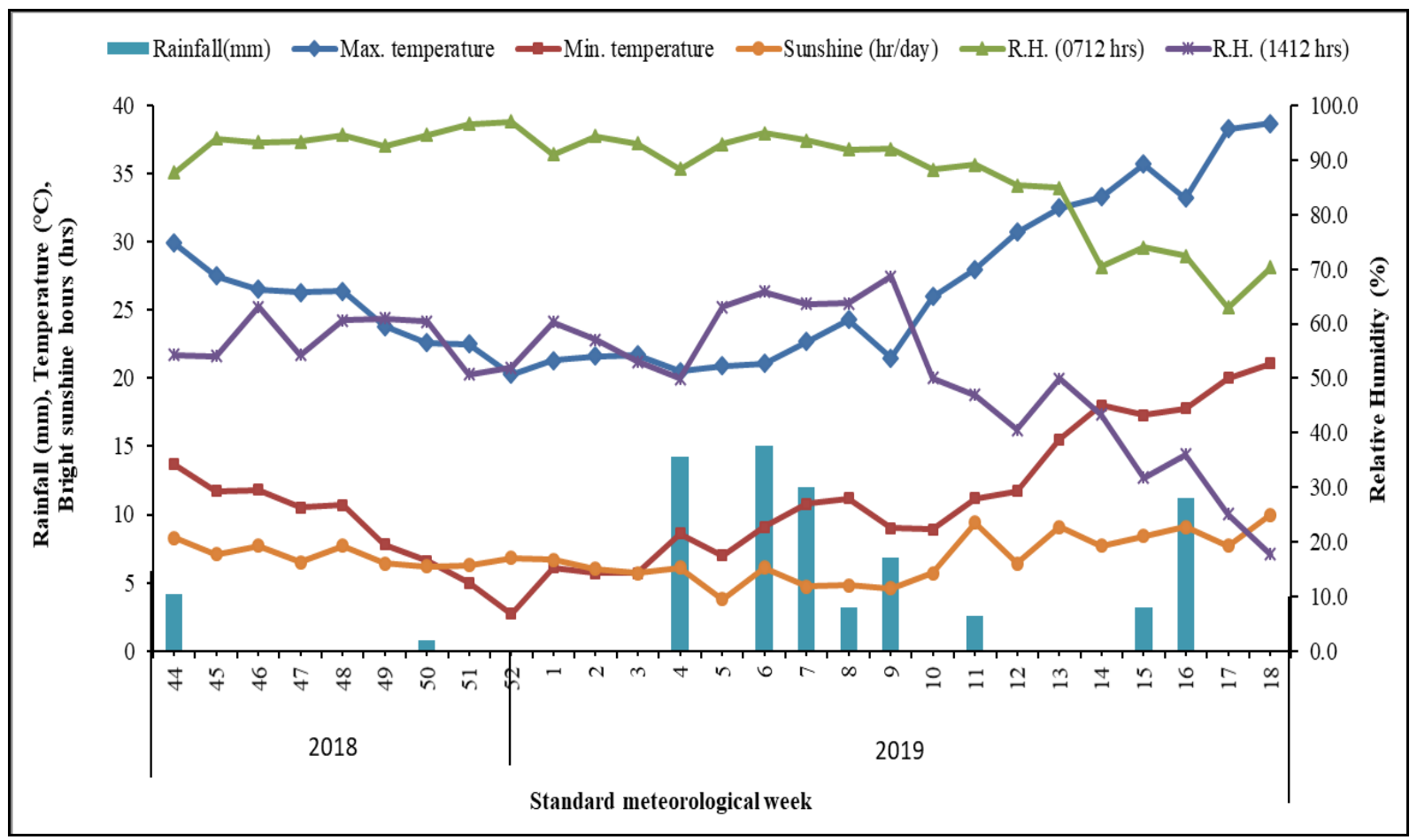

Table.1 Effect of tillage systems and residue loads on emergence count of wheat

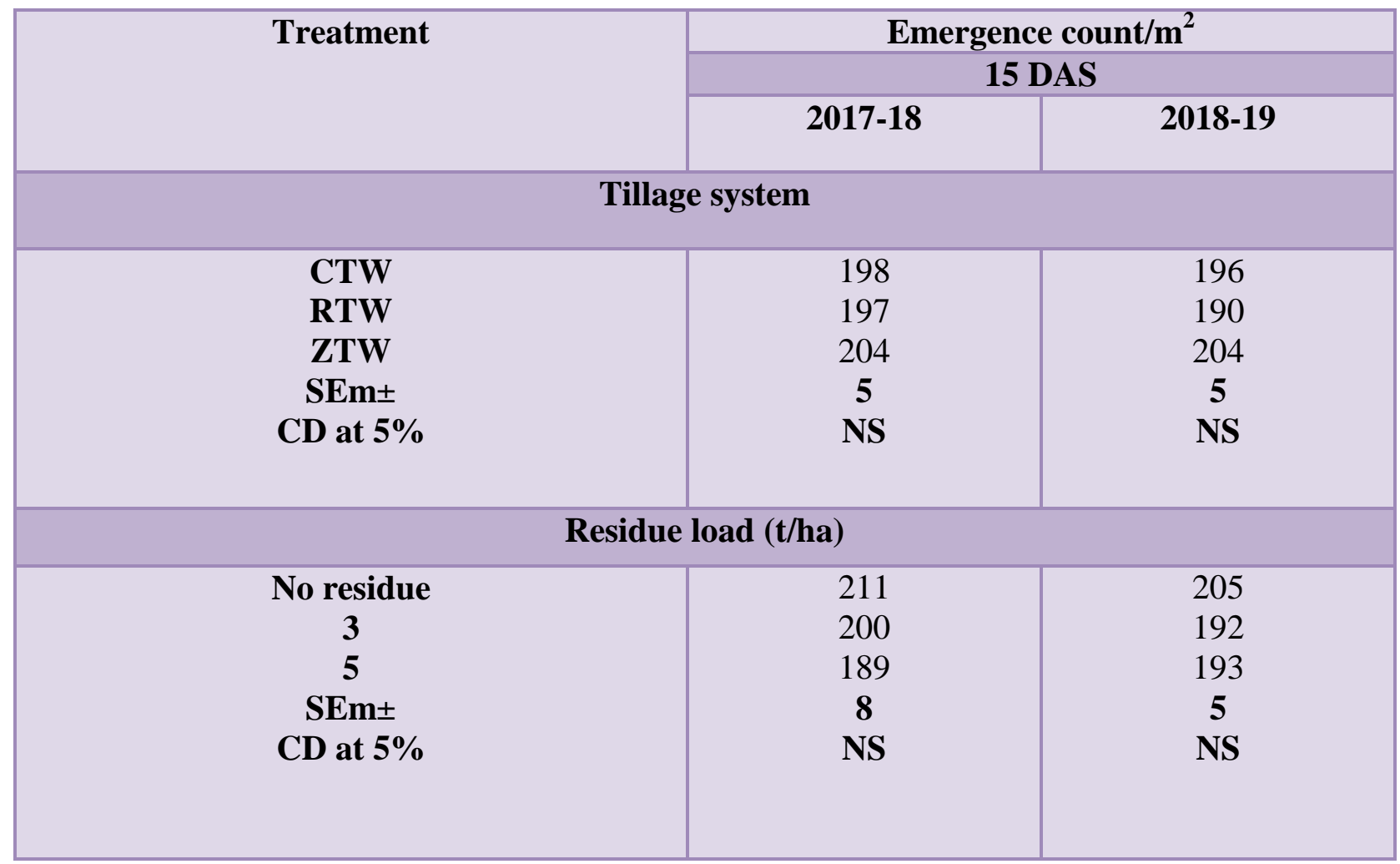


Table.2 Effect of tillage systems and residue loads on number of shoots $/ \mathrm{m}^{2}$ of wheat crop at various growth stages

\begin{tabular}{|c|c|c|c|c|}
\hline \multirow[t]{3}{*}{ Treatment } & \multicolumn{4}{|c|}{ Number of shoots $/ \mathrm{m}^{2}$} \\
\hline & \multicolumn{2}{|c|}{50 DAS } & \multicolumn{2}{|c|}{90 DAS } \\
\hline & 2017-18 & 2018-19 & 2017-18 & 2018-19 \\
\hline \multicolumn{5}{|c|}{ Tillage system } \\
\hline $\begin{array}{c}\text { CTW } \\
\text { RTW } \\
\text { ZTW } \\
\text { SEm } \pm \\
\text { CD at 5\% }\end{array}$ & $\begin{array}{c}540 \\
529 \\
517 \\
\mathbf{2 5} \\
\text { NS }\end{array}$ & $\begin{array}{c}525 \\
541 \\
537 \\
\mathbf{8} \\
\mathbf{N S}\end{array}$ & $\begin{array}{c}557 \\
546 \\
529 \\
\mathbf{1 7} \\
\mathbf{N S}\end{array}$ & $\begin{array}{c}549 \\
559 \\
545 \\
\mathbf{1 0} \\
\text { NS }\end{array}$ \\
\hline \multicolumn{5}{|c|}{ Residue load (t/ha) } \\
\hline $\begin{array}{c}\text { No residue } \\
3 \\
5 \\
\text { SEm } \pm \\
\text { CD at } 5 \% \\
\end{array}$ & $\begin{array}{c}535 \\
533 \\
516 \\
\mathbf{3 0} \\
\mathbf{N S}\end{array}$ & $\begin{array}{c}539 \\
545 \\
518 \\
\mathbf{6} \\
\mathbf{1 5}\end{array}$ & $\begin{array}{c}544 \\
558 \\
529 \\
\mathbf{7} \\
\mathbf{1 8} \\
\end{array}$ & $\begin{array}{c}551 \\
562 \\
539 \\
\mathbf{6} \\
\mathbf{1 7} \\
\end{array}$ \\
\hline
\end{tabular}

Table.3 Effect of tillage systems and residue loads on plant height $(\mathrm{cm})$ of wheat crop at various growth stages

\begin{tabular}{|c|c|c|c|c|c|c|}
\hline \multirow[t]{3}{*}{ Treatment } & \multicolumn{6}{|c|}{ Plant height (cm) } \\
\hline & \multicolumn{2}{|c|}{50 DAS } & \multicolumn{2}{|c|}{90 DAS } & \multicolumn{2}{|c|}{ At maturity } \\
\hline & 2017-18 & 2018-19 & 2017-18 & 2018-19 & 2017-18 & 2018-19 \\
\hline \multicolumn{7}{|c|}{ Tillage system } \\
\hline CTW & 37.9 & 35.9 & 56.4 & 55.8 & 92.1 & 88.8 \\
\hline RTW & 37.6 & 35.8 & 55.3 & 54.7 & 92.0 & 88.5 \\
\hline ZTW & 37.6 & 35.3 & 56.2 & 54.8 & 91.7 & 88.3 \\
\hline SEm \pm & 0.5 & 0.2 & 0.6 & 0.6 & 0.9 & 0.4 \\
\hline CD at $5 \%$ & NS & NS & NS & NS & NS & NS \\
\hline \multicolumn{7}{|c|}{ Residue load (t/ha) } \\
\hline No residue & 37.4 & 35.9 & 56.1 & 55.1 & 90.6 & 87.9 \\
\hline 3 & 38.4 & 35.8 & 56.3 & 56.2 & 92.9 & 88.5 \\
\hline 5 & 37.3 & 35.2 & 55.5 & 54.0 & 92.3 & 89.2 \\
\hline SEm \pm & 0.4 & 0.8 & 0.4 & 0.9 & 0.7 & 0.8 \\
\hline CD at $5 \%$ & NS & NS & NS & NS & NS & $\mathbf{N S}$ \\
\hline
\end{tabular}


Table.4 Effect of tillage systems and residue loads on dry matter accumulation $\left(\mathrm{g} / \mathrm{m}^{2}\right)$ of wheat crop at various growth stages

\begin{tabular}{|c|c|c|c|c|c|c|}
\hline \multirow[t]{3}{*}{ Treatment } & \multicolumn{6}{|c|}{ Dry matter accumulation $\left(\mathrm{g} / \mathrm{m}^{2}\right)$} \\
\hline & \multicolumn{2}{|c|}{50 DAS } & \multicolumn{2}{|c|}{90 DAS } & \multicolumn{2}{|c|}{ At maturity } \\
\hline & 2017-18 & 2018-19 & 2017-18 & 2018-19 & 2017-18 & 2018-19 \\
\hline \multicolumn{7}{|c|}{ Tillage system } \\
\hline CTW & 238.9 & 226.2 & 408.5 & 387.4 & 533.3 & 518.2 \\
\hline RTW & 236.9 & 219.9 & 410.2 & 386.3 & 538.5 & 519.0 \\
\hline ZTW & 232.4 & 218.6 & 411.4 & 381.9 & 533.0 & 519.3 \\
\hline SEm \pm & 3.9 & 4.2 & 5.6 & 6.2 & 5.2 & 3.0 \\
\hline CD at $5 \%$ & NS & NS & NS & NS & NS & NS \\
\hline \multicolumn{7}{|c|}{ Residue load (t/ha) } \\
\hline No residue & 234.6 & 219.7 & 411.8 & 386.3 & 538.4 & 512.3 \\
\hline 3 & 245.8 & 227.3 & 413.5 & 389.1 & 542.2 & 528.9 \\
\hline 5 & 227.7 & 217.7 & 404.8 & 380.2 & 524.2 & 515.4 \\
\hline SEm \pm & 2.3 & 9.2 & 5.0 & 8.7 & 4.4 & 5.3 \\
\hline CD at 5\% & 6.3 & NS & NS & NS & 12.25 & NS \\
\hline
\end{tabular}

Table.5 Effect of tillage systems and residue loads on yield of wheat crop

\begin{tabular}{|c|c|c|}
\hline \multirow[t]{2}{*}{ Treatment } & \multicolumn{2}{|c|}{ Grain yield (t/ha) } \\
\hline & 2017-18 & 2018-19 \\
\hline \multicolumn{3}{|c|}{ Tillage system } \\
\hline CTW & 4.62 & 4.78 \\
\hline RTW & 4.88 & 4.82 \\
\hline ZTW & 4.72 & 4.76 \\
\hline SEm \pm & 0.06 & 0.08 \\
\hline CD at $5 \%$ & 0.17 & NS \\
\hline \multicolumn{3}{|c|}{ Residue load (t/ha) } \\
\hline No residue & 4.73 & 4.81 \\
\hline $\mathbf{3}$ & 4.81 & 4.84 \\
\hline 5 & 4.69 & 4.71 \\
\hline SEm \pm & 0.08 & 0.27 \\
\hline CD at $5 \%$ & NS & NS \\
\hline
\end{tabular}

\section{Dry matter accumulation}

With the advancement of crop age, there was a progressive increase in the dry matter accumulation and the maximum value reached at maturity. In general, the dry matter accumulation was recorded higher in the first year as compared to second year. In both the years, tillage systems did not affect the dry matter accumulation of wheat significantly (Table 4). Numerically, RTW and ZTW recorded the maximum dry matter accumulation at maturity during first and second year, respectively. The dry matter production was not influenced significantly due to different residue loads during second year while, in the first year, dry matter accumulation got influenced significantly by 
residue load at 50 DAS and at maturity stage. The maximum dry matter accumulation was recorded under the treatments where $3 \mathrm{t} / \mathrm{ha}$ residue was maintained at the time of wheat sowing which was followed by the treatments in which no residue and 5 t/ha residue was maintained at $50 \mathrm{DAS}$ and at maturity.

The magnitude of increase in dry matter accumulation of $3 \mathrm{t} / \mathrm{ha}$ over no residue and 5 t/ha residue load was $0.71,3.43$ and 3.23 , $2.62 \%$ at maturity in the first and second year, respectively. The higher dry matter accumulation of wheat under $3 \mathrm{t} / \mathrm{ha}$ residue load might be attributed to increased plant height and the better rhizospheric and soil moisture conditions which led to better root growth which in turn, resulted in better nutrient and water uptake, thus, recorded maximum dry matter production.

\section{Grain yield}

Tillage systems did influence the grain yield significantly in the first year only. Tillage systems did not affect the grain yield significantly in the second year (Table 5). Reduced tilled wheat recorded the maximum grain yield (4.88 t/ha) being at par with ZTW (4.72 t/ha) and significantly higher over CTW in the first year. The magnitude of increase in grain yield by RTW over ZTW and CTW was 3.39 and $5.63 \%$, respectively in the first year. In the next year, ZTW recorded comparable grain yield with CTW and RTW. The difference of $3.39 \%$ in grain yield between RTW and ZTW in first year got decreased to $1.26 \%$ in the second year.

The reasons being attributed to higher grain yield in RTW during first year were higher dry matter accumulation, number of grains/spike and grain weight/spike. The major contributing factors for comparable grain yield in ZTW for second year were higher dry matter accumulation, grain weight/spike, 1000-grain weight and number of grains/spike. Similar findings were reported by Gangwar et al., (2005) and Sirazuddin et al., (2015). Residue loads did not influence the grain yield during both the years of experimentation, though the maximum grain yield was recorded under 3 $\mathrm{t} / \mathrm{ha}$ residue load followed by no residue and 5 t/ha residue load. It reveals that both removal and excess of residues are not desirable. Medium residue load is easily manageable and helps in better soil environment with respect to moisture and nutrient release, which is evident from better growth and yield attributing characters, particularly the spike number and grain weight per spike.

On the basis of experimental findings, it is concluded that sowing through happy seeder in zero tillage wheat with residue load of 3 t/ha is possible and gives comparable grain yield with conventional tillage.

\section{References}

Gangwar, K.S., Singh, K.K., Sharma, S.K. and Tomar, O.K. 2005. Alternative tillage and crop residue management in wheat after rice in sandy loam soils of Indo-Gangetic plains. Soil Till. Res. 88: 242-252.

Mandal, K. G., Misra, A. K., Hati, K. M., Bandyopadhyay, K. K., Ghosh, P. K., and Mohanty, M. 2004. Rice residue management options and effects on soil properties and crop productivity. Food, Agriculture and Environment, 2: 224231.

Rajkhowa, D. J. and Borah, D. 2008. Effect of rice (Oryza sativa) straw management on growth and yield of wheat (Triticum aestivam). Indian Journal of Agronomy, 53(2): 112-115.

Sirazuddin, Singh, S. P., Singh, V. P., Mahapatra, B. S. and Verma, H. 2016. Effect of weed-control measures on 
yield, weed control, economics, energetics and soil microflora under different establishment methods of
Wheat (Triticum aestivum L.).Intern. J. of Bio. and St. Manag. 2016, 6(6): 736743

\section{How to cite this article:}

Sirazuddin, V. Pratap. Singh, Subhash Chandra, S.P. Singh, S.K. Guru, Navneet Pareek, Arya Kumar Sarvadamana and Arunima Paliwal. 2019. Growth and Productivity of Wheat under Tillage Systems and Residue Loads in Tarai Region of Uttarakhand, India. Int.J.Curr.Microbiol.App.Sci. 8(08): 11-19. doi: https://doi.org/10.20546/ijcmas.2019.808.003 